\title{
MASTITE BOVINA: UMA REVISÃO
}

Wallacy Barbacena Rosa dos Santos ${ }^{1}$, Nariane Coelho de Oliveira², Milena de Lima Vieira², Jeferson Corrêa Ribeiro ${ }^{1}$, Andréia Santos Cezário', Eliandra Maria Bianchini Oliveira ${ }^{1}$, Aline Sousa Camargos ${ }^{1}$, Tiago Neves Pereira Valente ${ }^{3}$

${ }^{1}$ Instituto Federal de Educação, Ciência e Tecnologia Goiano - IF GOIANO, Dept. de Zootecnia, Morrinhos, GO. ${ }^{2}$ Instituto Federal de Educação, Ciência e Tecnologia Goiano - IFGOIANO, Curso de Zootecnia, Morrinhos, GO. ${ }^{3}$ Instituto Federal de Educação, Ciência e Tecnologia Goiano - IFGOIANO, Posse, GO. E-mail: wallacy.barbacena@ifgoiano.edu.br

\section{RESUMO}

A mastite, processo inflamatório da glândula mamária, caracteriza-se por determinar queda na produção e alterações na composição do leite, sendo considerada a doença de maior impacto para a bovinocultura no Brasil. Normalmente, essa doença é resultante da ação de agentes infecciosos, podendo estar envolvidas diferentes espécies de vírus, fungos, micoplasmas e, principalmente, bactérias. É importante lembrar que a mastite, de qualquer forma ou intensidade, reduz a produção leiteira, chegando a muitos casos a perda de um ou mais tetos. Assim, o controle da mastite bovina é essencial para a produção de leite de boa qualidade. Objetivou-se com esta revisão um estudo a respeito dessa patologia que acomete os rebanhos leiteiros, por afetar de maneira severa a produção e qualidade do leite, afetando todos os envolvidos: produtores, laticínios e consumidores dos produtos lácteos.

Palavras-chave: composição do leite; gado leiteiro; glândula mamária.

\section{BOVINE MASTITE: A REVIEW}

\section{ABSTRACT}

The mastite, inflammation process of mammary gland, characterized by a decrease in production and changes in milk composition, is considered the disease of major impact for dairy cattle in Brazil. Normally, this disease is resultant of the action of infectious agents, and may be involved different species of virus, fungi, and mainly, bacteria. It is important to remember, that the mastite, of any form and effect, reduces milk production and, in severe cases, may occur loss of one or more teats. Thus, the control of bovine mastite is important for the milk production of high quality. The aim of study is develop a study about this pathology that affects the dairy cattle and their effects in production and quality milk, and consequently, farmers, dairy industry and their products.

Keywords: milk composition; dairy cattle; mammary gland.

\section{INTRODUÇÃO}

É possível observar que em todas as áreas de produção há sempre uma preocupação maior com a qualidade dos produtos. E esse fato é responsável pela busca de melhorias em todas as etapas de produção, e, a qualidade pode ser um fator crucial para a sobrevivência da competitividade entre empresas. O mercado agroindustrial do leite é um dos mais importantes do agronegócio brasileiro, sempre levando em consideração os aspectos econômicos e sociais. A 
produção leiteira está presente em todo o território brasileiro, atuando no suprimento de alimentos, na renda de quem o produz e gerando empregos (GOMES, 2001).

O leite é considerado o mais nobre dos alimentos, dada a sua composição peculiar rica em proteínas, gordura, carboidratos, sais minerais e vitaminas. Entre os leites explorados comercialmente, destaca-se o bovino, tanto pela sua produção como principalmente pelo seu consumo (ASSIS et al., 2007). De acordo com Borges et al. (2009), o setor da pecuária leiteira é um dos mais importantes do Brasil, devido a sua importância sócio econômica, e que apesar de gerar divisas, a qualidade da matéria-prima ainda é um grande entrave ao desenvolvimento tecnológico dos laticínios.

Há diversos fatores que afetam a composição do leite, porém, pesquisas indicam que mais de $60 \%$ das variações na composição do leite são influenciadas por fatores genéticos, os outros fatores são os ambientais, relacionados ao estádio de lactação, prática de ordenha e clima, além do manejo da alimentação, nutrição e incidência de doenças. Como no caso da mastite, que é uma doença que reduz a produção de leite, bem como a sua qualidade nutricional (SILVA; VELOSO, 2011).

Para Tozzetti et al. (2011), a mastite bovina é a doença mais comum e mais cara do gado leiteiro, e pode ser causada por estresse e ferimentos físicos, porém, a infecção por bactérias invasivas e outros microrganismos, como fungos, leveduras e possivelmente vírus são as principais causas de mastite. A mastite é um processo inflamatório do úbere, acompanhado da redução de secreção de leite e mudança de permeabilidade da membrana que separa o leite do sangue (COELHO et al., 2016).

A mastite pode ser dividida basicamente em dois tipos, mastite clínica e subclínica. A forma clínica é caracterizada por alguns sintomas, tais como, edema no úbere, endurecimento dos tetos, presença de grumos, pus e sangue no leite, entre outros. Já a forma subclínica, se caracteriza por alterações na composição do leite, entretanto, não há sinais claros como o tipo clínico, o sinal mais evidente é a queda de produção e de qualidade do leite (LOPES et al., 2015).

Todavia, a mastite em qualquer um dos tipos, ou de diferente intensidades, implica na redução da produção leiteira e gastos com medicamentos. A mastite é um problema complexo e, às vezes, de difícil solução porque é uma doença causada por uma série de fatores ou circunstâncias que se interagem (PIRES et al., 2004; LOPES et al., 2015).

Objetivou-se com esta revisão um estudo a respeito dessa patologia que acomete os rebanhos leiteiros, por afetar de maneira severa a produção e qualidade do leite, afetando todos os envolvidos: produtores, laticínios e consumidores.

\section{Glândula Mamária}

Para uma melhor compreensão de como ocorre a produção de leite e de como essa produção pode ser influenciada, é importante conhecer um pouco da anatomia e fisiologia da glândula mamária, assim, de acordo com Tronco (2010), a anatomia constitutiva do animal e os fatores fisiológicos que comandam a capacidade de produção, armazenamento e descida do leite para a cisterna do úbere mostram como a natureza planejou tudo sistematicamente.

A glândula mamária é uma diferenciação especial do tecido da pele, e localiza-se fora das paredes do corpo do animal, a qual se mantém unida por meio de suportes de tecido conectivo, possuindo diversos vasos circulatórios e nervos que chegam até ela por meio do canal inguinal abaixo da pele (TRONCO, 2010; BRAGA et al., 2015).

As glândulas mamárias são glândulas sudoríparas modificadas, que produzem leite para a nutrição da prole e desenvolvem-se a partir de espessamentos bilaterais do ectoderma ventrolateral do embrião, as chamadas linhas do leite, conhecidas mais corretamente como cristas mamárias (FRANDSON et al., 2011; PARK et al., 2006). 
O úbere da vaca é constituído por quatro glândulas individuais, conhecidas como quartos mamários, onde cada lado do úbere é quase completamente independente do outro, mesmo que o suprimento sanguíneo, o nervoso e o aparelho suspensor sejam compartilhados, todo o leite de um teto é produzido pelo tecido glandular daquele quarto mamário, apenas (FRANDSON et al., 2011; FERREIRA et al., 2017).

A glândula mamária é composta por um grupo de células chamadas de alvéolos, que produzem e secretam o leite, e desses alvéolos partem pequenos canais que vão para os grandes ductos e chegam a um receptor maior, que é a cisterna da glândula, e depois para a cisterna do teto (TRONCO, 2010). Para Silva e Veloso (2011), os alvéolos tem três funções básicas: remover nutrientes do sangue; transformar esses nutrientes em leite; e descarregar o leite dentro do lúmen.

O úbere é composto por bilhões de alvéolos, nos quais o leite é secretado, a ejeção do leite ocorre somente quando as células mioepiteliais que recobrem os alvéolos e os ductos menores, contraem em resposta ao hormônio ocitocina, causando o chamado reflexo da descida do leite, para que o leite flua de dentro dos alvéolos, ductos galactóforos, cisterna da glândula e cisterna do teto para o meio externo (SILVA; VELOSO, 2011).

A atividade secretora da mama encontra-se na dependência de um complexo lactogênico elaborado pelo lóbulo anterior da hipófise, e este complexo hormonal só intervém após o desaparecimento quase completo da foliculina e da progesterona, como consequência do parto, e os hormônios que possuem atividade lactogênica comprovada são: a prolactina, o hormônio do crescimento e o hormônio placentário lactogênico ou somatotropina coriônica (TRONCO, 2010).

Por ser um órgão extremamente especializado, é importante a compreensão de alguns fundamentos relacionados a glândula mamária. Os quartos mamários são glândulas individuais, ou seja, não há interligação com as demais, se uma for afetada pela mastite, não necessariamente os outros três quartos mamários estarão. A glândula mamária apresenta vasta irrigação por artérias e veias que suprem o sistema com os nutrientes necessários para a síntese do leite (NETO, 2010).

Para Carneiro et al. (2009) a imunidade da glândula mamária pode ser classificada em inata ou inespecífica e adaptativa ou específica, onde a imunidade inata é a defesa predominante durante os estágios iniciais da infecção, assim, as respostas inespecíficas estão presentes no local da infecção ou são ativadas rapidamente por inúmeros estímulos e não há aumento em decorrência da exposição repetida ao mesmo agente etiológico, e para se estabelecerem na glândula mamária e iniciarem o processo infeccioso, os patógenos necessitam inicialmente escapar da resposta imune inata.

\section{Patógenos da Mastite}

O leite fica exposto a uma série de influências de natureza físico-química e a grande número de contaminações, e isso ocorre desde a sua obtenção até o seu consumo. Os microrganismos normalmente utilizam como substrato, os componentes do leite, incluindo proteína, gordura, lactose e outros constituintes menores (TRONCO, 2010). Distúrbios fisiológicos da glândula mamária, em decorrência de danos físicos leves ou invasão por materiais inertes, podem resultar em mastite de curta duração, entretanto, as mastites geralmente são causadas por infecção bacteriana (BRITO; BRESSAN, 1996; SOUZA et al., 2009).

Os patógenos envolvidos na incidência de mastite bovina possuem muitos fatores de virulência que facilitam a colonização e infecção da glândula mamária, e alguns deles podem evadir-se às defesas do hospedeiro ao se aderirem às células epiteliais, produzindo cápsulas que dificultam a captura e destruição pelos neutrófilos, produzindo endotoxinas e exotoxinas que destroem ou inativam os leucócitos, ou se mantem no interior das células para escapar à resposta imune (CARNEIRO et al., 2009). 
As diversas formas de mastite causadas pelas diferentes bactérias, têm diferentes patogêneses. Mesmo para um patógeno particular, ocorrem grandes variações, e geralmente considera-se que todos os patógenos penetram a glândula mamária através do canal da teta, embora o modo e o tempo de entrada possam diferir enormemente entre eles (BRITO; BRESSAN, 1996).

De acordo com Brito et al. (2002), aproximadamente 95\% das infecções que resultam em mastite são causadas pelas bactérias Streptococcus agalactiae, S. aureus, Streptococcus dysgalactiae, Streptococcus uberis, Mycoplasma bovis e Escherichia coli (Tabela 1). Os outros 5\% são causados por outros microrganismos, e todos são classificados em dois grupos: contagiosos e os ambientais.

Benedette et al. (2008), afirmam que para haver essa classificação, é necessário levar em consideração a origem do inoculo infeccioso, que no caso da mastite contagiosa, os principais agentes etiológicos são as bactérias e no caso dos patógenos ambientais são inclusos as espécies de estreptococos. No grupo dos coliformes ambientais, encontram-se as bactérias Gram-negativas (Escherichia coli, Klebsiella spp., Citrobacter spp., Enterobacter spp., E. faecalis e E. faecium).

Tabela 1. Principais agentes etiológicos da mastite e suas características.

\begin{tabular}{ll}
\hline Agente Etiológico & Características \\
\hline \multirow{3}{*}{ Streptococcus agalactiae } & Habita o úbere e não sobrevive fora da glândula por longos \\
& períodos. É susceptível a penicilina e, uma vez eliminado, não \\
& é novamente isolado dos animais, a não ser que vacas \\
& infectadas sejam introduzidas ao rebanho. \\
\hline & É um microrganismo encontrado no úbere, na pele e nos \\
& pelos dos animai, em abscessos e férias, na pele do ser \\
& humano e de diversos animais, e em vários outros locais e \\
Staphylococcus aureus & materiais. Dificilmente é eliminado dos rebanhos, mas ode \\
& ser controlado efetivamente com a adoção de manejos \\
& higiênicos, especialmente durante a ordenha. É \\
& moderadamente susceptível a antibióticos, quando a \\
& infecção é detectada no início.
\end{tabular}

Streptococcus dysgalactiae pele, fezes e currais. E pode ser controlado com medidas corretas de higiene. Essa espécie é moderadamente susceptível a antibióticos.

É um microrganismo que ocupa posição intermediaria entre Mycoplasma bovis bactérias e vírus. Com não existe um tratamento eficaz disponível, o controle desse patógenos se faz evitando sua introdução no rebanho, por meio de animais infectados.

O S. uberis e outros streptococos (exceto S. agalactiae), habitam todos os espaços da fazenda, sendo mais

Streptococcus uberis frequentemente isolados das fezes, úbere, pele dos animais, rúmen. Podem ser controlados com a manutenção de úberes sempre secos, ambiente de ordenha limpo e higiene geral adequada.

A Escherichia coli e outras bactérias do grupo dos coliformes (Klebisella e Enterobacter), são encontradas no trato Escherichia coli intestinal de todos os animais e podem ser recuperadas nos dejetos, águas poluídas e em camas de material orgânico (palha, serragem, maravalha, raspas de madeira), 
contaminadas com fezes.

Fonte: Brito et al. (2002).

De acordo com a Embrapa (2011), as mastites contagiosa e ambiental podem ser caracterizadas da seguinte forma:

- Mastite contagiosa - os casos são caracterizados pela maior incidência da forma subclínica. São geralmente de longa duração, com alta CCS e são causados por microrganismos que tem como habitat a própria glândula mamária e a pele dos tetos. A transmissão acontece principalmente no momento da ordenha, por meio de teteiras, e pelo manejo dos ordenhadores.

- Mastite ambiental - é causada por agente cujo reservatório é o próprio ambiente onde há acúmulo de esterco, urina, barro e camas orgânicas. Este tipo de mastite é caracterizado pela maior incidência da forma clínica da doença, geralmente de curta duração e com manifestação aguda. A infecção, ou maior parte dela, ocorre no período entre ordenhas, embora possa ser transmitida em situações de problemas de funcionamento de equipamento. A mastite ambiental pode acometer todas as categorias animais, vacas lactantes, secas ou novilhas, já a forma contagiosa é mais comum nas vacas em lactação.

\section{Diagnóstico}

Para evitar que os tecidos internos do úbere sejam gravemente afetados, é indicado que haja um diagnóstico precoce, ou seja, na fase inicial da mastite, assim permitindo a eficácia do tratamento e consequente recuperação dos tecidos, também evitando a disseminação da doença pelo rebanho, permitindo que a qualidade inicial do leite seja preservada (VEIGA, 1998).

Segundo Radostits et al. (2007), para um eficaz e correto diagnóstico da mastite bovina, são recomendados exames microbiológicos do leite, porém, o procedimento de coleta das amostras para análise, tem de ser feita em todos os quartos mamários individualizados, tais procedimentos corroboram para o conhecimento do estado sanitário do rebanho, no que diz respeito à referida infecção (DELLA LIBERA et al., 2011).

Moeini et al. (2002), afirma que a real importância de se diagnosticar vacas com mastite subclínica e aparentemente sadias, é descobrir quais animais podem ser transmissores de infecção pela linha de ordenha ou pela mão do ordenhador.

Estes animais além de serem focos de contaminações, contribuem pela baixa qualidade do leite e menor volume total produzido, o que reflete em perdas econômicas à propriedade (DIAS, 2007), promovendo também alterações na composição do leite, tais como aumento na CCS e alterações nos teores de caseína, cálcio, gordura e lactose (RIBEIRO et al., 2003), determinando menor rendimento na produção dos seus derivados e diminuindo o tempo de prateleira dos mesmos (DIAS, 2007).

O diagnóstico da mastite subclínica é detectado pelos testes indiretos, realizados no leite das vacas, que são o California Mastitis Test (CMT) e CCS (contagem de células somáticas no leite do tanque de resfriamento), utilizando contadores eletrônicos que mensuram anticorpos, enzimas associadas a células e o aumento da condutividade elétrica do leite (BENEDETTE et al, 2008).

\section{Teste CMT (California Mastistis Test)}

O California Mastitis Test (CMT) é um teste que pode ser realizado no campo, é muito prático e barato, embora deva ser executado por profissional devidamente treinado (EMBRAPA, 2011). De acordo com Radostits et al., (2000) a contagem de células somáticas no leite pode ser estimada pelo CMT estabelecendo-se escores que, normalmente, variam de 1 a 5 , onde, o escore 1 indica uma reação completamente negativa e os de 2 a 5 indicam graus crescentes de inflamações do úbere, sendo considerados indicativos de mastite subclínica. 
Esses níveis podem ser analisados de forma crescente, onde podemos considerá-los: negativo, suspeito, fracamente positivo, positivo e fortemente positivo, de 1 a 5 , respectivamente. Os escores 3, 4 e 5 devem ser considerados como positivos para a mastite (RIET-CORREA et al., 2001). O princípio do teste baseia-se na reação do detergente aniônico, que atua sobre as células presentes no leite, rompendo suas membranas e liberando o material nuclear dos leucócitos, a liberação desse material produz aumento da viscosidade (TRONCO, 2010).

Para Brito et al. (2002), o CMT deveria ser realizado a cada 15 dias em rebanhos com problemas e, pelo menos uma vez por mês, nos demais rebanhos, visando identificar animais com alta CCS, porém, há uma desvantagem no CMT, pois, ele apenas estima o conteúdo de células de forma subjetiva, o que exige do operador discernimento na leitura e interpretação dos resultados.

As amostras de leite que apresentarem positividade para o CMT, devem ser colhidas e enviadas para analise em laboratório, para averiguação do agente etiológico da mastite, e nos procedimentos de coleta das amostras, os tetos dos animais devem ser lavados com boa quantidade de água, secos com toalhas de papel e desinfetados com álcool 70\%, desprezando os primeiros jatos de leite, coletar as amostras em frascos estéreis de preferência fornecidos pelo laboratório responsável pelas análises, o material é colocado em isopor com gelo e encaminhado o mais breve possível ao laboratório (RIET-CORREA et al., 2001; BARBOSA et al., 2002).

\section{Teste da caneca telada ou fundo escuro}

Em um programa de sanidade animal, é imprescindível a utilização da caneca telada, pois esse teste avalia a aparência do leite, onde os primeiros jatos de leite de cada quarto mamário na caneca de fundo telado ou escuro, permite a detecção de anormalidades no leite (coloração aguada, grumos, sangue, pus, coágulos, entre outros). Este teste deve ser executado em todas as ordenhas, pois é possível a detecção da mastite clínica nos primeiros jatos de leite (DE PAULA MOREIRA et al., 2007).

Quando há a presença de mastite clínica no quarto mamário do animal, ocorre um depósito de leucócitos no canal da teta, e estes leucócitos são responsáveis pela formação dos grumos, pus, coágulos, entre outras alterações que são visualizadas nos primeiros jatos de leite. Portanto, esses primeiros jatos de leite devem ser depositados na caneca de fundo escuro ou telada para que as alterações físicas do leite possam ser observadas com mais facilidade, devido ao contraste do fundo da caneca com as alterações do leite que ficam mais aparentes (EMBRAPA, 2011).

\section{Cultura bacteriana}

Esse teste pode auxiliar no diagnóstico da mastite, onde uma porção de leite 'suspeito' ou afetado é enviada ao laboratório para a realização do exame bacteriológico, assim, o exame identifica o agente infeccioso causador da doença, o que facilita o tratamento da mesma, principalmente se for realizado junto com o antibiograma (EMBRAPA, 2011).

Este tipo de teste é complementar aos feitos 'ao pé' do animal, ou em plataformas de recepção de industrias ou mesmo em laboratórios, as bactérias isoladas das culturas podem ser testadas para resistência aos antibióticos e assim servir de guia na seleção dos medicamentos (PIRES et al., 2004).

Tozzetti et al. (2011), relataram que esse tipo de teste geralmente é feito em vacas selecionadas a partir da contagem de células somáticas de amostras compostas caso ela revele um problema sério e persistente, onde esse tipo de cultura de leite de cada vaca identifica as espécies bacterianas que as acometem, sendo assim a maneira mais confiável para se decidir quanto ao melhor tratamento com antibiótico para uma determinada vaca. 


\section{Mastite Clínica}

Na mastite clínica, podem ser observados sinais de inflamação, como calor, dor e endurecimento da glândula mamária, acompanhados de sintomatologia sistêmica, como febre depressão e anorexia (RIET-CORREA et al., 2001), esses sintomas se devem mais à ação de toxinas liberadas pelas bactérias do que propriamente à infecção (BRITO et al., 2002). Uma vez identificada a mastite clínica, o animal deve ser retirado da sala de ordenha, voltando para ser ordenhado após a ordenha dos animais sadios (EMBRAPA, 2011).

Para Brito et al. (2002), em rebanhos com problemas de mastite clínica deve-se avaliar cuidadosamente a dimensão do problema, ou seja, é necessário consultar os registros de todos os casos clínicos ocorridos no rebanho, e se não houver essas informações, deve-se iniciar o registro para futuras avaliações, devendo conter a identificação do animal, a ordem de parição, data da ocorrência (em relação ao parto), o medicamento usado e a duração do tratamento. Esses registros auxiliam na identificação das vacas que são responsáveis pela maioria dos casos clínicos, e assim, se necessário, providenciar o descarte desses animais (CASSOL et al., 2010).

\section{Mastite Subclínica}

Na mastite subclínica não é possível observar alterações nas glândulas mamárias e nem no leite, esse tipo de mastite somente é diagnosticada por meio de cultura bacteriana, ou por testes que demonstrem altas taxas de leucócitos no leite (RIET-CORREA et al., 2001). A mastite subclínica, além de ser a forma mais frequente, proporciona os maiores prejuízos ao produtor e à indústria de laticínios, uma vez que causa "silenciosa" redução da capacidade de secreção láctea do quarto mamário afetado (PARDO et al., 2015)

Para Brito et al. (2002) a avaliação da mastite subclínica em animais e nos rebanhos pode ser feita por meio de exames microbiológicos, que permitem identificar a fonte de infecção no rebanho, podendo também determinar o padrão de susceptibilidade aos antimicrobianos, o que pode dar suporte na escolha do antibiótico a ser usado na terapia da vaca seca, que é um dos procedimentos mais eficazes para o controle da mastite subclínica, e tem como objetivo eliminar as infecções subclínicas existentes e prevenir as infecções de ocorrência comum no início do período seco (OLIVEIRA et al., 2014).

A mastite subclínica, é responsável por 90 a 95\% dos casos de mastite no rebanho, onde apresenta uma prevalência quinze a quarenta vezes maior que a forma clínica da doença, todavia, mesmo a mastite subclínica sendo responsável pelo maior prejuízo do produtor, a prevalência da doença é subestimada uma vez que para efeito de análise, apenas os casos de mastite clínica são considerados (EMBRAPA, 2011).

Considera-se que para cada caso de mastite clínica ocorram cerca de vinte a cinquenta casos de mastite subclínica em um rebanho (BRITO et al., 2002). De acordo com Fetrow et al. (2000), nos Estados Unidos, a diminuição da produção de leite associada à mastite subclínica em rebanhos típicos, representa de $70 \%$ a $80 \%$ de todas as perdas econômicas advindas da mastite.

\section{Mastite Crônica}

Riet-Correa et al. (2001), ao discorrer sobre os tipos de mastite, menciona que para a mastite crônica, é importante verificar se há alterações no leite, tais alterações que geralmente são evidentes, podendo ser observados sangue ou flocos de caseína, ou aspecto aquoso, outras alterações também podem ocorrer como aumento do volume da glândula mamária por abscessos ou granulomas, fistulas, atrofia de quartos mamários, entre outros. Caso seja constatado que o animal é portador de mastite crônica, a indicação é de que o mesmo tem de ser descartado (EMBRAPA, 2011).

Em estudos conduzidos por Demeu et al. (2011) onde objetivaram analisar e quantificar a influência do descarte involuntário de matrizes no impacto econômico da mastite em rebanhos 
leiteiros, constatou-se que os animais cronicamente acometidos por mastite e descartados, ocasionaram maior desvalorização de matrizes, elevando os valores das perdas e, consequentemente, o impacto econômico total por vaca em lactação e por $\mathrm{kg}$ de leite comercializado.

\section{Contagem de Células Somáticas (CCS)}

Todas as células presentes no leite são consideradas células somáticas, e isso inclui as células originárias da corrente sanguínea como leucócitos e células de descamação do epitélio glandular secretor, onde os leucócitos, em sua maioria, são mobilizados da corrente sanguínea para o tecido mamário diante de alterações na permeabilidade capilar (MÜLLER, 2002). Diversos fatores podem exercer influência na variação da contagem celular somática de vacas em lactação, como idade, período de lactação, ordem de parto, estação do ano, entre outros (HARMON, 1994).

A CCS é um exame realizado em laboratórios especializados, é feita em equipamentos automatizados que possibilita a análise de várias amostras, e, é utilizado para o diagnóstico da mastite subclínica, ou seja, os leucócitos tem a função de fagocitar e digerir os microrganismos invasores, dessa forma, quando há uma infecção da glândula mamária a contagem de células somáticas (CCS) aumenta, diagnosticando a mastite subclínica (EMBRAPA, 2011; NASCIMENTO et al., 2016).

Outro modo de mensurar as células somáticas é por meio de exame microscópico de lâminas coradas, este método serve de referência para os demais, porém, é laborioso, mais caro e não permite automação (BRITO et al., 2002). Todos os métodos instrumentais para a detecção da mastite fundamentam-se na contagem de células somáticas existentes no leite, razão pela qual um dos principais sintomas da doença, já em seu estado subclínico, é justamente o aumento do número de células somáticas do leite produzido pelo animal doente (TRONCO, 2010).

A contagem de células somáticas está relacionada com as perdas de produção no rebanho, pois, mais de $98 \%$ das células somáticas encontradas no leite vêm das células sanguíneas brancas que entram no leite em resposta a invasão bacteriana no úbere (TOZZETTI et al., 2008).

Estima-se que, de $2 \%$ a $20 \%$, da contagem celular somática, são de células epiteliais, advindas da descamação natural que ocorre no tecido de revestimento e secretor interno da glândula mamária, todas essas células geralmente estão presentes em pequeno número (até 50.000 ou mesmo 100.000 por $\mathrm{ml}$, no úbere sadio), entretanto, em presença de inflamação, em alguns casos podem alcançar vários milhões por ml (BRITO et al., 2002).

A International Dairy Federation (1981) estabeleceu como limite máximo para leite normal 500.000 células somáticas (cél/ml) no leite, dessa forma, esse limite tornou-se base para países exportadores e os que pretendem exportar leite.

Entretanto, no Brasil, o Ministério da Agricultura, Pecuária e Abastecimento alterou a legislação que rege a produção de leite, primeiramente através da Instrução Normativa $n^{\circ} 51$, e recentemente foi instaurada a Normativa $n^{\circ} 62$, que em seu texto afirma que a partir de 01/07/2016 as Regiões Centro-Oeste, Sudeste e Sul, e a partir de 01/07/2017 - Regiões Norte e Nordeste, o leite será considerado dentro dos padrões da legislação se não exceder o valor de 400.000 células/ml/leite.

A adoção de limites máximos para a CCS do leite bovino, é uma tendência mundial em busca de maior qualidade de matéria prima, consequentemente, dos derivados lácteos (TRONCO, 2010).

\section{Controle e Profilaxia}

Em qualquer sistema de produção animal, o melhor controle de enfermidades é a prevenção, portanto, a busca por orientação técnica é imprescindível e o estabelecimento de 
programas de higiene e prevenção de doenças são necessários para a boa produtividade do rebanho.

Comumente, há produtores que não possuem o hábito de tratar os animais no momento da secagem, o que é um método preventivo importante, pois atua antes que o quadro seja mais severo, uma vez que, a vaca no período seco irá recuperar sua glândula mamária para a próxima lactação e eliminar os casos de mastite subclínica presentes no rebanho (NETO, 2010).

E para a Embrapa (2011), as vacas secas devem ser tratadas com medicamentos próprios para essa fase, pois existem no mercado vários medicamentos para tratamento preventivo de vacas, contudo, é bom lembrar que estes medicamentos nunca devem ser utilizados para tratar mastites comuns, pois são próprios para prevenção da mastite no período seco, portanto, o ideal é sempre consultar um médico veterinário quando o caso exigir tratamento com medicamentos.

Para Riet-Correa et al. (2001) o sucesso do controle da mastite bovina acontece quando a taxa de infecção é mantida baixa ou bem reduzida, seja através da prevenção de novas infecções ou da eliminação das infecções já existentes, onde, geralmente as mudanças não ocorrem rapidamente, porém, devem ser suficientes para convencer o produtor que a estratégia adotada é correta.

Para isso é necessário que o programa de sanidade animal integre diversas medidas que devem ser estabelecidas simultaneamente, como diagnóstico da infecção, ordenha, controle da ordenhadeira mecânica, tratamento e manejo das vacas infectadas (SAALFELD et al., 2013).

A Embrapa (2011), indica a utilização de uma 'linha de ordenha', que é um manejo recomendado para melhorar o controle das ocorrências de mastite, nesse manejo primeiramente são ordenhadas as vacas sadias, depois as vacas que já foram acometidas pela mastite e foram curadas e ao final da linha, ordenhar as vacas com mastite e as que estão em tratamento, e se a mastite se apresentar de forma muito intensa o animal deve ser ordenhado fora do local de ordenha para não contaminar o ambiente.

Para Tozzetti et al., (2011), além do descarte seletivo de animais infectados, recuperação espontânea, tratamento durante a lactação e tratamento a secagem, a redução da duração das infecções pode ser obtida, também, por meio de uso correto de antimicrobianos e outros agentes terapêuticos no tratamento da mastite clínica e no tratamento à secagem, pois, aproximadamente 20 a 30\% das infecções da glândula mamária são eliminadas espontaneamente pelo sistema de defesa do animal.

De acordo com a Embrapa (2011), é necessário empenho na prevenção e no controle da mastite, pelo fato de tratar-se de uma doença que pode surgir repentinamente e por ser uma doença relacionada ao manejo.

Para realizar uma prevenção adequada, é preciso levar em consideração todo o manejo da propriedade, e atentar aos índices da doença, como por exemplo, quando os índices se elevam, é indicativo de que provavelmente uma ou mais ações dentro do manejo estão sendo executadas de forma inadequada (WINCK; NETO, 2014).

Em qualquer programa de controle, tem que ser dada atenção especial ao treinamento e capacitação da mão de obra (WINCK; NETO, 2014), e que um bom programa de controle e prevenção da mastite deve incluir pelo menos alguns itens, como adequação do ambiente, manejo de dejetos, condução dos animais até a ordenha, deteç̧ão de mastite, preparação do úbere para a ordenha, desinfecção de tetas antes da ordenha, desinfecção de tetas pós-ordenha, manutenção dos animais de pé após a ordenha, tratamento dos casos clínicos, terapia da vaca seca, descarte de animais, aquisição de novos animais, alimentação adequada e monitoramento da mastite no rebanho (BRITO et al., 2002).

E, segundo Pires et al., (2004), há algumas medidas curativas alternativas, e que independentemente da terapêutica adotada no tratamento das mastites, deve-se ter sempre em mente que as infecções podem ser eliminadas de quatro maneiras: 
- Recuperação espontânea: onde $20 \%$ dos casos são resolvidos desta forma, graças aos mecanismos de defesa do animal;

- Uso de terapia durante a lactação: essa medida deve ser restringida aos casos clínicos, já que a efetividade nos casos subclínicos é baixa (30 a 40\%) e os custos são altos com medicamentos, descarte do leite, mão-de-obra, entre outros;

- Terapia no início do período seco: essa medida apresenta uma taxa de cura de $80 \%$ a $90 \%$, muito eficiente para os microrganismos contagiosos e pouco eficiente para os microrganismos do ambiente e;

- Descarte dos animais infectados.

O controle da mastite é de suma importância para obter uma produção de leite de boa qualidade, e realizando a antissepsia dos tetos por meio de banhos de imersão com desinfetantes adequados pode reduzir novas infecções em 50 a 90\% (PEDRINI; MARGATHO, 2003).

\section{Prejuízos Associados à Mastite}

Os prejuízos acarretados pela mastite bovina atinge os produtores rurais, as indústrias beneficiadas com a matéria-prima e os consumidores, que estão sujeitos a problemas de saúde decorrentes da presença de agentes patológicos no leite e seus derivados (PARDO et al., 2015), nesse sentido, estima-se que, mundialmente as perdas anuais causadas pela doença são por volta de 35 bilhões de dólares (BENEDETTE et al, 2008).

A taxa de mastite dos rebanho pode ser estimada com base na CCS, de acordo com estudos realizados em vários países (Tabela 2). As graves perdas econômicas relacionadas a mastite são devidas a redução na produção de leite e a interferência com a qualidade e o encurtamento da vida de prateleira do leite processado e seus derivados (BRITO et al., 2002).

Para Tronco (2010), a mastite provoca uma série de alterações físico-químicas no leite, como: modificações no pH (geralmente deixando-o alcalino), diminuição no extrato seco total (caseína, gordura, lactose), aumento de minerais, como sódio e cloro, diminuição do cálcio e fósforo, aumento de algumas enzimas (catalase, fosfatase ácida, arilestearase, entre outras), ressaltando ainda os problemas com o sabor (sabor salgado), fermentações anormais, demora de coagulação, dificuldade de sinéreses dos queijos, diminuição do rendimento, da termoestabilidade, que constituem os principais problemas tecnológicos observados na indústria, decorrentes do uso do leite mastítico.

Tabela 2. Interpretação da CCS do rebanho, de acordo com a gravidade provocada pela mastite e a redução da produção de leite.

\begin{tabular}{lll}
\hline $\begin{array}{l}\text { CCS no leite do rebanho } \\
(\mathbf{1 . 0 0 0 )} \text { (células/mL) }\end{array}$ & $\begin{array}{l}\text { Estimativa da Gravidade da } \\
\text { Mastite }\end{array}$ & $\begin{array}{l}\text { Redução da Produção de Leite } \\
\text { (\%) }\end{array}$ \\
\hline$<250$ & Pouca ou nenhuma & Irrelevante \\
\hline 250 a 500 & Média & 4 \\
\hline 500 a 750 & Acima da média & 7 \\
\hline 750 a 1.000 & Ruim & 15 \\
\hline$>1.000$ & Muito ruim & 18 \\
\hline Adaptado de Brito et al. (2002) & &
\end{tabular}

Adaptado de Brito et al. (2002).

Para Cassol et al., (2010), além dos prejuízos econômicos acarretados pela mastite bovina, outro problema relacionado a essa doença, é a propagação de zoonoses, subsidiar reações alérgicas e eventual toxidade do leite, provenientes da utilização de antibióticos no controle da infecção, assim, representando riscos para à saúde dos consumidores.

Prejuízos acarretados pela mastite vão desde a baixa qualidade do leite a muito além dos portões das propriedades rurais (COSTA, 1991). Mudanças na composição do leite, como redução 
em cálcio, fósforo, proteína e gordura, e aumento em sódio e cloro, são componentes que reduzem sua qualidade, e a utilização de antibióticos para tratar a mastite é uma preocupação importante para a indústria e para a saúde pública, pois a presença de resíduo de antibiótico no leite interfere com o processo de manufaturação de muitos produtos lácteos: queijo, iogurte e outros produtos fermentáveis (TOZZETTI et al., 2008).

\section{CONSIDERAÇÕES FINAIS}

As alterações inflamatórias da glândula mamária geradas pela mastite, podem gerar inúmeros prejuízos que vão desde os produtores, às indústrias e até ao consumidor, este último sendo o mais preocupante. É importante lembrar que a mastite de qualquer forma ou intensidade reduz a produção leiteira, chegando em muitos casos a perda de um ou mais tetos. $E$ ao considerar a representatividade que o setor pecuário tem na economia do País, fica claro a importância de se conhecer bem os fatores que influenciam a disseminação de uma doença como a mastite, que gera tantas perdas.

\section{REFERÊNCIAS}

ASSIS, E.M de; FARIA, M.G; RODRIGUES, F.C. Qualidade do leite Bovino e Efeitos de seu consumo sobre a saúde. Higiene alimentar. V.21, no 156, novembro, 2007. CARVALHO, M.P. de. Melhoria da qualidade do leite: reflexões.

COELHO, K.O.; BRANDÃO, L.M.; BUENO, C.P.; MELO, C.S.; SILVEIRA NETO, O.J. Níveis de células somáticas sobre o perfil físico-químico do leite em pó integral. Ciência Animal Brasileira, v. 17, n. 4, p. 534-539, 2016. https://doi.org/10.1590/1089-6891v17i417203

BARBOSA, C.P.; BENEDETTI, E.; RIBEIRO, S.C.A.; GUIMARÃES, E.C. Relação entre contagem de células somáticas (CCS) e os resultados do "California Mastitis Test"(CMT), no diagnóstico de mastite bovina. Bioscience Journal, v. 18, n. 1, p. 93-102, 2002.

BENEDETTE, M. F. et al. Mastite bovina. Rev. Cien. Elet. Med. Vet, v. 11, 2008.

BORGES, K.A.; REICHERT, S.; ZANELA, M.B.; FISCHER, V. Avaliação da qualidade do leite de propriedades da região do Vale do Taquari no estado do Rio Grande do Sul. Acta Scientiae Veterinariae. v. 37, n. 1, p. 39-44, 2009.

BRAGA, R.A. et al. MORFOFISIOLOGIA, AFECÇÕES E DIAGNÓSTICO ULTRASSONOGRÁFICO DA GLÂNDULA MAMÁRIA EM BOVINOS: REVISÃO DE LITERATURA. Nucleus Animalium, v. 7, n. 1, 2015.

BRITO, J.R.F.; BRESSAN, M. Controle integrado da mastite bovina. Juiz de Fora: EMBRAPA-CNPGL, 1996. 111p.

BRITO, J.R.F.; BRITO, M.A.V; ARCURI, E.F. Como reconhecer e controlar a mastite em rebanhos bovinos. Juiz de Fora: Embrapa gado de Leite, 2002. 8p. (Embrapa Gado de Leite: Circular Técnico, 70).

CARNEIRO, D.M.V.F.; DOMINGUES, P.F.; VAZ, A.K. Imunidade inata da glândula mamária bovina: resposta à infecção. Ciência Rural, v. 39, n. 6, 2009. https://doi.org/10.1590/S010384782009005000106 
CASSOL, D. M. S. et al. Mastite bovina. A Hora Veterinaria, Ribeirão Preto, v. 29, n. 175, p.27-31. 2010.

COSTA, E.O. Importância econômica da mastite infecciosa bovina. Comun. cient. Fac. Med. Vet. Zootec. Univ. Säo Paulo, v. 15, n. 1, p. 21-6, 1991.

DELLA LIBERA, A.M.M.P.; SOUZA, F.N.; BLAGITZ, M.G.; BATISTA, C.F. Avaliação de indicadores inflamatórios no diagnóstico da mastite bovina. Arquivos do Instituto Biológico, v. 78, n. 2, p. 297 300, 2011.

DEMEU, F.A.; LOPES, M.A.; COSTA, G.D.; ROCHA, C.M.B.M.; SANTOS, G.D.; FRANCO NETO, A. Influência do descarte involuntário de matrizes no impacto econômico da mastite em rebanhos leiteiros. Ciência e Agrotecnologia, v. 35, n. 1, p. 195-202, 2011. https://doi.org/10.1590/S1413$\underline{70542011000100025}$

DE PAULA MOREIRA, M.S.; RIBEIRO, A.C.D.C.L., COSTA, A.C.; SANTOS, C.A.; ARCURI, E.F.; DINIZ, F.H.; ... e BRITO, M.A.V.P. Kit Embrapa de ordenha manual. Embrapa Gado de Leite, 2007.

DIAS, R.V.C. Principais métodos de diagnóstico e controle da mastite bovina. Acta Veterinária Brasílica, Mossoró, v.1, n.1, p.23-27, 2007.

EMBRAPA. Centro Nacional de Pesquisa de Gado de Leite (Juiz de Fora). Controle da mastite. 2011.

FERREIRA, R.C.; GIANNONE, P.H.; MORAIS, K.M.; SOARES, V.; OLIVEIRA, M.V.M. AVALIAÇÃO MORFOLÓGICA DE BOVINOS DAS RAÇAS PANTANEIRA E GIROLANDO CRIADOS EM CONDIÇÕES “IN SITU”. ANAIS DO SEMEX, n. 9, 2017.

FETROW, J. et al. Mastitis: an economic consideration. In: ANNUAL MEETING OF THE NATIONAL MASTITIS COUNCIL, 39., 2000, Atlanta. Proceedings... Madison: National Mastitis Council, 2000. p. 3-47.

FRANDSON, R.D.; WILKE, W.L.; FAILS, A.D. Anatomia e Fisiologia dos Animais de Fazenda. Guanabara Koogan, 2011. cap. 29.

GOMES, S.T. Diagnóstico e perspectivas da produção de leite no Brasil. In: VILELA, D.; BRESSAN, M.; CUNHA, A.S. (Org.). Cadeia de lácteos no Brasil: restrições ao seu desenvolvimento. Brasília/Juíz de Fora: MCT/ CNPq - EMBRAPA, 2001. P.21-35.

HARMON, R.J. Physiology of mastitis and factors affecting somatic cell counts. J. Dairy Sci., v.77, p.2103-2113, 1994. https://doi.org/10.3168/jds.S0022-0302(94)77153-8

IDF - International Dairy Federation. 1981. The IDF group of experts on mastitis. Laboratory methods for use in mastitis word. Inter. Dairy Fed. 132:3-27.

LOPES, L.; LACERDA, M.; RONDA, J. Uso de antibióticos na cura e controle de mastite clínica e subclínica causada por principais microorganismos contagiosos em bovinos leiteiros: revisão de literatura. Revista Cientifica Eletrônica de Medicina Veterinária, v. 21, n. 1, p. 1-15, 2015. 
MOEINI, M. M.; SANJABI, M. R.; AHADI, A. H. High bacteria count in milk and it's economic loss. IN: WORLD BUIATRICS CONGRESS, 22., 2002, Hannover. Abstracts...Hannover: Proceedings, 2002. p. 9-10.

MÜLLER, E.E. Qualidade do leite, células somáticas e prevenção da mastite. In: Simpósio sobre Sustentabilidade da Pecuária Leiteira na Região Sul do Brasil, v. 2, p. 206-217, 2002.

NASCIMENTO, K. B. et al. Efeito da contagem de células somáticas sobre a composição do leite de vacas girolando. Revista de Educação Continuada em Medicina Veterinária e Zootecnia, v. 14, n. 3, p. 72-72, 2016.

NETO, O.A.P. Fundamentos da mastite bovina e seus impactos na produção. 2010.

OLIVEIRA, A.J.; MORAES, G.F.; FERREIRA, I.C.; MONTEIRO, C.P.; CARVALHO, A.D.F. Mastite clínica e subclínica em pequenas propriedades leiteiras no município de Araguari-MG. Veterinária Notícias, v. 19, n. 1, p. 7-13, 2014.

PARDO, R.B.; STURION, D.J.; BASILE, J.R.; FRANCISCO, A.C.N.; SILVA DUARTE, D. D.; FERNANDES, A.A.; ... PANÍCIO, E.M. Levantamento dos agentes etiológicos da mastite bovina na região de Arapongas (PR). Journal of Health Sciences, v. 1, n. 1, 2015.

PARK, C. S. et al. Glândula mamária e lactação. Dukes: Fisiologia dos Animais domésticos. Ed. Guanabara Koogan SA, v. 12, p. 670-690, 2006.

PEDRINI, S. C. B.; MARGATHO, L. F. F. Sensibilidade de microrganismos patogênicos isolados de casos de mastite clínica em bovinos frente a diferentes tipos de desinfetantes. Biológico, São Paulo, v. 70, n. 4, p. 391-395, 2003.

PIRES, M.F.A.; BRITO, J.R.F.; BRITO, M.A.V.P. Homeopatia: uma opção de tratamento da mamite bovina. Juiz de Fora: Embrapa Gado de Leite, 2004. 40p. (Embrapa Gado de Leite. Documentos, 100).

RADOSTITS, O. M., GAY, C. C., BLOOD, D. C., HINCHCLIFF, K. W. Clínica Veterinária - Um tratado de Doenças dos Bovinos, Suínos, Caprinos e Equinos. 9a ed., Rio de Janeiro: Guanabara Koogan, 2000. p. 541-628.

RADOSTITS, O.M.; GAY, C.C.; HINCHCLIFF, K.W; CONSTABLE, P.D. Veterinary medicine: a textbook of the diseases of cattle, horses, sheep, pigs and goats. 10nd ed.. Philadelphia: Saunders Elsevier, 2007. $2156 \mathrm{p}$.

RIBEIRO, M.E.R. et al. Relação entre mastite clínica, subclínica infecciosa e não infecciosa em unidades de produção leiteira na região sul do Rio Grande do Sul. Revista Brasileira Agrociência. 9(3):287-290. 2003.

RIET-CORREA, F. et al. Doenças de ruminantes e equinos. São Paulo. Varela, p. 294-307. 2001.

SAALFELD, M.H.; ROSA, M.C.; PEREIRA, D.B.; BORCHARDT, J.L.; LEITE, F.P.L. 13940-Avaliação microbiológica e do período de validade de selante a base de linhaça utilizado pós ordenha no controle de mastite bovina. Cadernos de Agroecologia, v. 8, n. 2, 2013. 
SANTOS, M.V.; FONSECA, L.F.L. Estratégias para controle de mastite e melhoria da qualidade do leite. São Paulo: Manole, 2007.

SILVA, J.C.P.M. da; VELOSO, C. M. Manejo para maior qualidade do leite. Viçosa, MG: Aprenda Fácil, 2011.

SOUZA, G.N.; BRITO, J.R.; MOREIRA, E.C.; BRITO, M.A.V.; SILVA, M.V.G. Variação da contagem de células somáticas em vacas leiteiras de acordo com patógenos da mastite. Arq. bras. med. vet. zootec, v. 61, n. 5, p. 1015-1020, 2009. https://doi.org/10.1590/S0102-09352009000500001

TOZZETTI, D. S. et al. Prevenção, controle e tratamento das mastites bovinas - revisão de literatura. Revista científica eletrônica de medicina veterinária, v. 6, n. 10, 2008.

TRONCO, V.M. Manual para inspeção da qualidade do leite. 4. ed. Santa Maria: Ed. UFSM, 2010. VEIGA, V.M.O. Diagnóstico da mastite bovina. Juíz de Fora: EMBRAPA-CNPG-ADT, 1998.

WINCK, C.A.; NETO, A.T. Diagnóstico da adequação de propriedades leiteiras em Santa Catarina às normas brasileiras de qualidade do leite. Revista de Ciências Agroveterinárias, v. 8, n. 2, p. 164172, 2014. 